\title{
Analyzing Search Styles of Patrons and Staff: A Replicative Study of Two University Libraries
}

\section{Kathlin L. Ray and Mary S. Lang}

\begin{abstract}
Librarians at the University of the Pacific (UOP) designed a replication of an earlier transaction log study. We hypothesized that library staff would use a feature that allows the searcher to limit a search by location or material type more often than patrons. We also hypothesized that staff and reference librarians would have a higher success rate than public users. Our third hypothesis was that UOP patrons would perform keyword searches more often than library staff. Studies were conducted in 1995 and 1996 to test these hypotheses. In our two-year endeavor to provide comparative data on the search styles of patrons and staff, we discovered that replicating a study is not nearly as straightforward as we had initially thought. We also found it surprisingly difficult to compare year to year data at the same institution. This was primarily due to a continually changing technological environment.
\end{abstract}

I

In a recent article on patron and staff searching styles at Adelphi University Library, Ballard (1994) urged librarians using Innovative Interfaces Inc. Innopac software to collect and analyze system data in order to compare results. Accepting the challenge, librarians at the University of the Pacific designed a replication of Ballard's transaction log study. The decision to replicate this research was a conscious attempt to produce data that would allow us to compare results of two similar institutions. UOP has 4,100 students and Adelphi has 5,600. Both universities have a main library and a science branch. The library collections are roughly similar in size (UOP, 410,000 volumes, Adelphi, $303,000)$, and both have fewer than 2,700

periodical titles. Staffing is considerably different, however; UOP employs 10.5 librarians, 20 support staff, and 115 student assistants while Adelphi employs 23 librarians, 35 support staff, and 11 student assistants (data from American Library Directory, 49th ed. 1996-97).

While we were interested in comparing UOP and Adelphi patron search patterns, we were particularly eager to compare staff search styles. Until Ballard's work, transaction log studies of library staff searches were virtually nonexistent (Peters 1993). Concurring with Ballard, we hypothesized that staff would use a feature that allows the searcher to limit a search by location or material type more often than patrons. We also hypothesized

Kathlin L. Ray (kray@uop.edu) is Head, Access Services, University of the Pacific Libraries, Stockton, CA. MARY S. LANG (mlang@uop.edu) is Catalog Librarian, University of the Pacific Libraries, Stockton, CA. Manuscript received MMMM DD, 1997; accepted for publication MMMM DD, 1997. 
that staff and reference librarians would have a higher success rate-i.e. fewer zero retrievals-than public users. Our third hypothesis, contrary to Ballard, was that UOP patrons would perform keyword searches more often than library staff.

We assumed that search patterns of UOP patrons and staff would be similar to the search patterns of Adelphi patrons and staff. Ballard (1994) found that patrons and library staff had very different searching strategies, with staff going beyond the standard author, title, subject, and keyword searches eight times more often than patrons. Ballard found that patrons at Adelphi searched most often by subject $(35.5 \%)$ with title searches a close second (31\%), author third (21\%), and keyword a distant fourth (8\%). Library staff searched most often by title $(46 \%)$, then by other options such as international standard number or barcode (32\%), third by author or subject (16.6\%), and fourth by keyword (5\%). Staff used the limit feature more often (3\%) than the public $(2 \%)$. In our study, surprisingly, we found that UOP patrons searched the system quite differently than users at Adelphi, preferring keyword searches to subject, title, or author searches. UOP staff, like staff at Adelphi, searched most often by title and least often by subject (public services staff) or keyword (technical services staff).

\section{LITERATURe Review}

Transaction log analysis (TLA), according to Peters (1989) is an excellent, cost-effective way to determine how patrons use online catalogs. In the 30 years since the first TLA studies were conducted in the late 1960s, researchers have analyzed system logs to answer basic questions about computerized catalogs and their users. Peters $(1993,42)$ found that the types of TLA studies conducted, and the results obtained, were "amazingly diverse" even when researchers investigated the same questions-despite being focused primarily on patron search behaviors, system response times, and preferred search commands. Despite the quantity of studies, wide variations in library com- puter systems, data gathering techniques, time periods studied, and system search options have made it difficult to compare results among studies.

\section{Search Strategies}

Confounding initial assumptions, two decades of analysis have shown that users often prefer to search by subject rather than by author or title (Ballard 1994; Hunter 1991; Larson 1991b; Simpson 1989; Tillotson 1995; Tolle 1983; Zink 1991). However, users also find subject searches to be the most frustrating, primarily due to their ignorance of $\mathrm{Li}$ brary of Congress Subject Headings $($ LCSH). As Markey (1984) and many others (e.g., Hunter 1991; Wallace 1993; Zink 1991) have pointed out, users do not understand the concept of a controlled vocabulary, the composition of $L C S H$, or the relationships among the headings. Subject searches are also notorious for retrieving either too many records or none at all (Hunter 1991; Larson 1991a; Peters 1989). And while "zero hit" searches do not necessarily denote an unsuccessful search, a high number of zero retrievals prompts concern about user failure.

Although researchers of many TLA analyses have concluded that users prefer subject searching, others indicate a user preference for keyword. Indeed, there is evidence that the frequency of keyword searching outstrips other types of searching and is more effective at retrieving results than are subject searches. Tillotson (1995) found that searching by keyword retrieved all relevant materials about $50 \%$ of the time while subject searches often retrieved nothing. She determined that the large record sets retrieved by keyword searches did not interfere with the quick discovery of useful citations. Larson (1991b) observed a consistent decline in the use of the subject index and a corresponding rise in the use of title keyword in his study of the University of California's MELVYL catalog. Martin, Wyman, and Madhok (1983) found that users of the SULIRS system at Syracuse University preferred to search by keyword (36\%) 
more often than by subject (26\%).

Furthermore, many researchers have recommended the use of keyword searching as a way to circumvent the frustrations of searches based on $\mathrm{LCSH}$ terms. Cherry (1992) suggested that catalogs be programmed to automatically run a keyword search on any subject search that retrieves zero hits. Zink (1991) advocated a "truth-in-labeling" approach to inform patrons of the difference between a keyword and an exact subject search. He recommended that the subject search screen include a statement instructing searchers to use $L C S H$ to construct queries.

Despite the popularity of subject and keyword searches, however, other researchers show title searching to be the preferred search strategy (Peters 1989; Cherry 1992; Connaway, Budd, and Kochtanek 1995). Cherry (1992) found that users performed title searches $52 \%$ of the time ( $16 \%$ of these were keyword title searches). Cherry found that keyword searching accounted for $16 \%$ and subject searching $17 \%$ of the total searches conducted. In another recent study, Connaway, Budd, and Kochtanek (1995) found that title searching exceeded LCSH subject and subject browse searches combined-which accounted for nearly one-third of all searches.

Transaction log research has played a major and vital role in increasing librarians' knowledge of patron search patterns and preferences. Unfortunately, data gathered from individual studies are not usually generalizable to a larger population. This is due to a variety of factors, including: the diversity of systems and search options, type of data collected, the fields searched, and time periods studied. For example, simply attempting to compare keyword search results is fraught with difficulties. A keyword search in some systems will look in subject, title and content notes fields; in other systems, keyword may invoke title fields only. One system may have separate keyword indexes for title, author and subject and another a browse mode that permits a quasi-keyword search. We hoped to overcome these obstacles by replicating a transaction log study conducted at an institution of similar size, using the same automated system, and following the same methodology.

\section{METHODOLOGY}

When we initiated the study in February 1995, public access to Innopac was available through twelve networked stations in the university's main and branch libraries. Five dial-up ports were available for remote users. Library staff accessed Innopac through 12 terminals and numerous PC workstations in offices. Staff occasionally searched at public terminals but agreed to restrict their work to nonpublic terminals during the three months of the study. Utilizing Innopac's ability to collect terminal-specific transaction data, we followed Ballard's example and created terminal groups according to the categories of users we wanted to study. We expanded Ballard's categories to include a separate category for reference librarians, hypothesizing that the search strategies of knowledgeable and experienced librarians would be very different than those of public users and even clerical staff. We created four terminal groups: (1) terminals used by public users, (2) terminals used by technical services staff, (3) terminals used by public services staff, and (4) terminals used by reference librarians. Innopac's data management system compiled detailed transaction data according to the terminal groups we designated.

Transaction logs for each terminal group were printed out and the file cleared every Wednesday. The first three weeks of data were used as a pretest in order to detect errors and fine tune the terminal groupings. By the last week in February, we were ready to begin the study. Every Wednesday at 7:00 a.m. for 14 weeks (from the fourth week of F ebruary through the third week of May) we printed out search data for each terminal group. The data were then entered into a spreadsheet and organized by month and type of search (see table 1). During the 


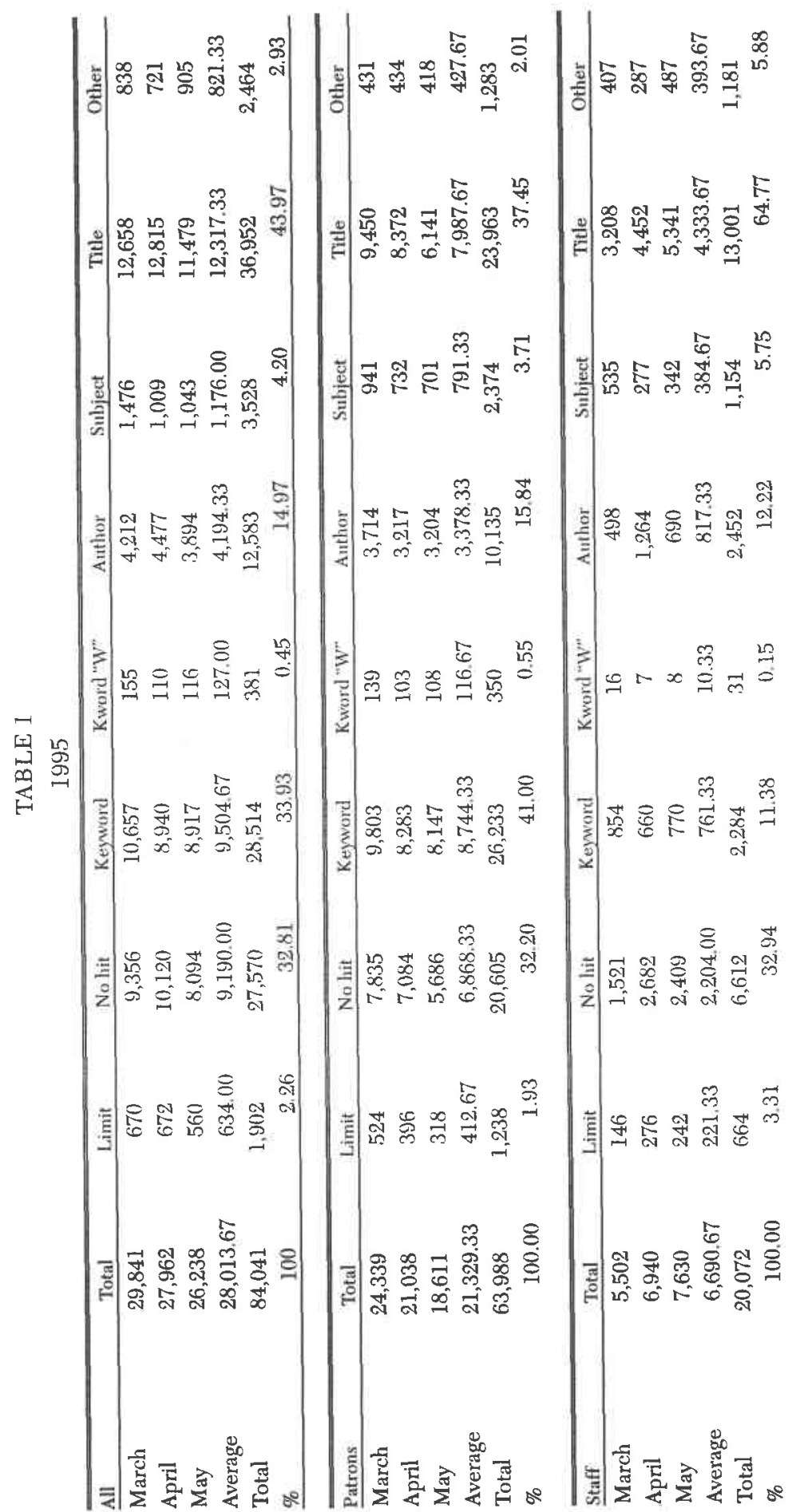




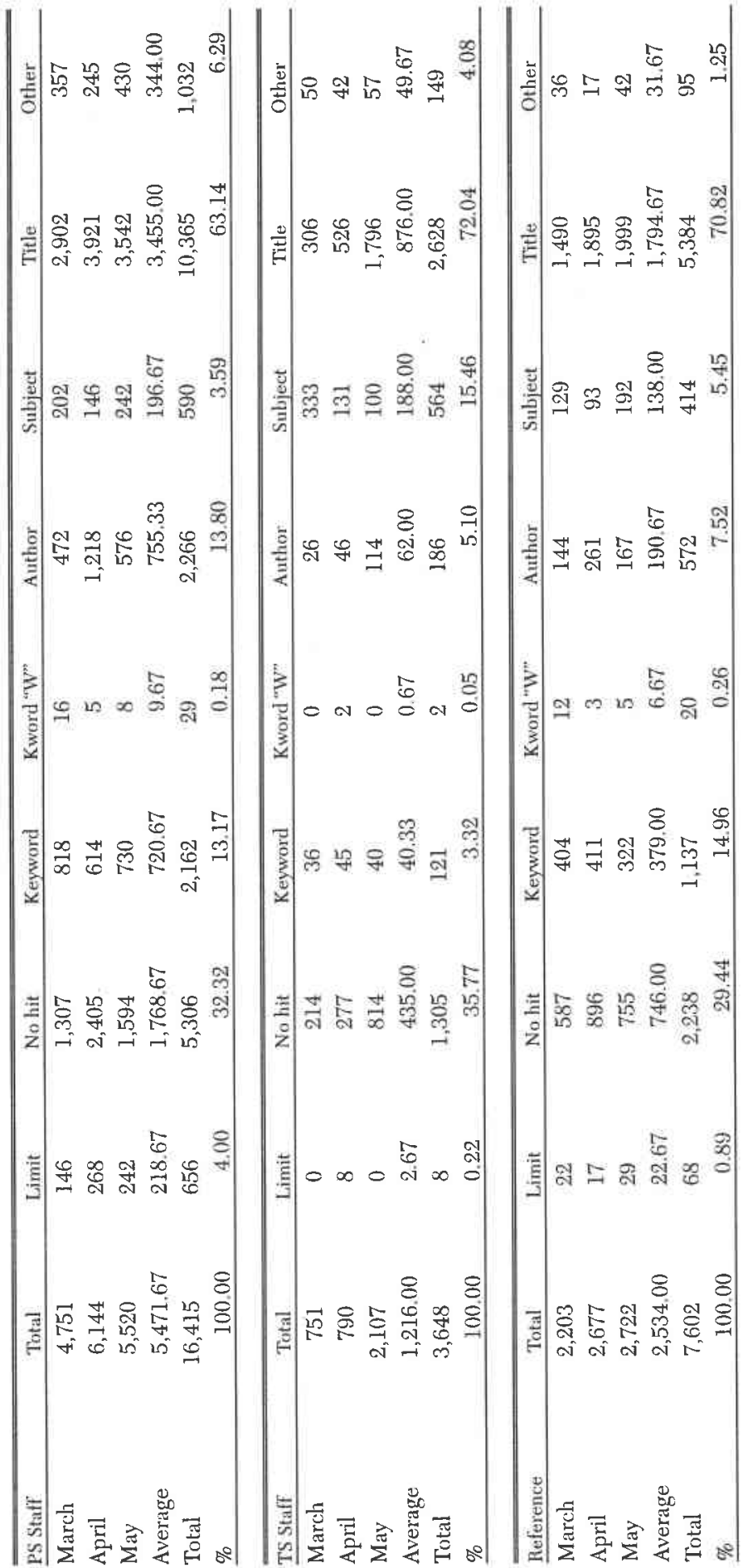


TABLE 2

Public Services Staff Catalog Searches

\begin{tabular}{lrrrr}
\hline & \multicolumn{2}{c}{ UOP 1995 } & \multicolumn{2}{c}{ Adelphi } \\
& $\%$ & Total & \multicolumn{1}{c}{$\%$} & Total \\
\hline Author & 13.8 & 2,266 & 9.3 & 1,695 \\
Title & 63.1 & 10,365 & 48.8 & 8,859 \\
Keyword & 13.2 & 2,162 & 7.9 & 1,432 \\
Subject & 3.6 & 590 & 10.6 & 1,918 \\
Other & 6.3 & 1,032 & 23.5 & 4,261 \\
Limit & 4.0 & 656 & 4.8 & 876 \\
Kword "w" & .2 & 29 & .5 & 84 \\
\hline
\end{tabular}

Technical Services Staff Catalog Searches

\begin{tabular}{lrrrr}
\hline & \multicolumn{2}{c}{ UOP 1995 } & \multicolumn{2}{c}{ Adelphi } \\
& \% & Total & \multicolumn{1}{c}{$\%$} & Total \\
\hline Author & 5.1 & 186 & 5.9 & 880 \\
Title & 72.0 & 2,628 & 34.1 & 5,091 \\
Keyword & 3.3 & 121 & 1.4 & 211 \\
Subject & 15.5 & 564 & 3.7 & 550 \\
Other & 4.1 & 149 & 54.8 & 8,176 \\
Limit & .2 & 8 & .4 & 61 \\
Kword “w” & .1 & 2 & .1 & 13 \\
\hline
\end{tabular}

Patron SEARChes

\begin{tabular}{lrrrr}
\hline \hline & \multicolumn{2}{c}{ UOP 1995 } & \multicolumn{2}{c}{ Adelphi } \\
& $\%$ & Total & \multicolumn{1}{c}{ Total } \\
\hline Author & 15.8 & 10,135 & 21.0 & 18,600 \\
Title & 37.5 & 23,963 & 31.1 & 27,544 \\
Keyword & 41.0 & 26,233 & 8.3 & 7,354 \\
Subject & 3.7 & 2,374 & 35.5 & 31,512 \\
Other & 2.0 & 1,283 & 4.1 & 3,649 \\
Limit & 1.9 & 1,238 & 1.8 & 1,627 \\
Kword "w" & .6 & 350 & 1.8 & 1,581 \\
\hline
\end{tabular}

study period there were a total of 84,041 staff and patron searches.

\section{Pilot Study Results}

The results were puzzling. The first anomaly was a substantially higher percentage of title searches by UOP library staff than at Adelphi (see table 2). Upon in- vestigation, we found that the high number of title searches might have been caused by the sizable one-time supplemental funds for collection development received by the library in early 1995 . Many staff members, in public services as well as technical services, were involved in checking the catalog for holdings, searching duplicate titles, etc. We also discov- 
Welcome to University of the Pacific

PacifiCat

You may search for library materials by any of the following:

\author{
A $>$ AUTHOR \\ T> TITLE \\ $\mathrm{K}>\mathrm{KEYWORDS}$ in the title, subject and contents \\ L $>$ Library of Congress Subject Headings \\ C>CALL NO \\ I $>$ INTERNATIONAL standard number \\ $\mathrm{H}>$ Library HELP and Information \\ R>RESERVE Lists \\ D>Connect to DATABASES, libraries and the Internet \\ Q> QUIT \\ Choose one (A, T,K,L,C,I,H,R,D,Q)
}

Older books (prior to 1982) may not be here; check the card catalog.

Please select the Library Help and Information screens $<\mathrm{H}>$ to learn more

about PacifiCat. For more assistance, ask at the Reference Desk.

Figure 1. UOP 1995 Introductory Search Screen.

ered that several reference librarians had been heavily involved in the collection development project and had routinely searched Innopac for titles while at the reference desk and when working in their offices. Since terminals in their offices and at the reference desk had been included in the reference terminal group, the data we collected did not accurately reflect the typical search strategies used by reference librarians.

The second and most dramatic anomaly was the unbelievably low number of subject searches $(3.7 \%)$ at public terminals and the unusually high number of keyword searches $(41 \%)$ in comparison to any study we had seen, especially in comparison to the one at Adelphi (see table 2). It was difficult to believe that our students really did search by keyword eleven times more often than by subject. We also looked closely at patron title searches. While the number of title searches performed by our users was not substantially higher than Adelphi's, we had observed a staff member using a public terminal during the course of the study. We were concerned that staff had skewed the patron data by using public terminals. While subsequent conversations calmed many of our misgivings, a couple of staff admitted they had forgotten and had used public terminals during the three months of the study. Searching infrequently and almost exclusively by title, staffimpact on total patron transactions was presumably minimal but remained a concern.

\section{Screen Menus}

From observation and user feedback, we suspected Innopac's search screens might have contributed to the atypical patron search patterns. On the main menu the keyword search option appeared just below author and title options (see figure 1 ). The subject search option, below keyword, was not labeled "Subject" but "Library of Congress Subject Headings" to emphasize the need to use a specific vocabulary. The naming and order of the search options had not been accidental. Following Zink's (1991) suggestion, the menu had been designed to encourage keyword searching and thereby reduce student frustration with $L C S H$ searches. Reference librarians had strongly empha- 
Welcome to University of the Pacific

PacifiCat

You may search for library materials by any of the following:

\author{
A $>$ AUTHOR \\ T>TITLE \\ $\mathrm{K}>\mathrm{KEYWORDS}$ in the title, subject and contents \\ S $>$ SUBJECT (Library of Congress Subject Headings) \\ $\mathrm{C}>\mathrm{CALL}$ NO \\ I $>$ INTERNATIONAL standard number \\ $\mathrm{H}>$ Library HELP and Information \\ R>RESERVE Lists \\ $\mathrm{V}>$ VIEW your circulation record \\ P $>$ Repeat PREVIOUS Search \\ Q RETURN TO GATEWAY MENU \\ Choose one (A,T,Y,K,S,C,I,H,R,V,P,Q)
}

Older books (prior to 1982) may not be listed; check the card catalog.

Please select the Library Help and Information screens $<\mathrm{H}>$ to learn more about PacifiCat. For more assistance, ask at the Reference Desk, 2433.

Figure 2. UOP 1996 Introductory Search Screen.

sized keyword searching in instruction sessions and one-on-one at the reference desk. Perhaps the effort had succeeded all too well; subject searching at the library had all but disappeared.

\section{STUdy}

Due to the obstacles encountered in the 1995 study, we decided to repeat the study one year later in February 1996. In addition to correcting any errors in the 1995 staff and patron search data, we wanted to look at the influence of the search menu and search option labels on patron search strategies. Given our findings in the 1995 study, we developed a hypothesis that the labeling of search options would have an effect on the way in which patrons searched the catalog. If the naming of an option influenced use patterns, then a change in search labels should cause a shift in the way the public used the system. The subject search option on the main menu was simply relabeled "Subject" followed by "Library of Congress Subject Headings" in parentheses (see figure 2). We retained the order of the options- keyword preceding subject-on the main search screen. Another factor, which had nothing to do with the design of our study but influenced the results nonetheless, was a change from an initial online catalog screen to a gateway screen in November 1995. This gateway menu highlighted periodical indexes and other libraries' catalogs and was the initial screen on all of our public stations (see figure 3 ).

In addition to making a change in the main search screen, we created a separate transaction group for terminals located at the reference desk only. Thus, we separated staff into three groups: reference staff on the one hand, and public and technical staff on the other. By excluding terminals in librarian offices we hoped the data would more clearly identify the search patterns of librarians at the reference desk, particularly their interactions with patrons. Terminals at the reference desk were only operational during the hours the desk was open. We added another transaction group to capture search patterns of remote users and began tracking searches that yielded record sets of 500 or more. Finally, we reminded staff 


\section{WELCOME TO UNIVERSITY OF THE PACIFIC LIBRARIES GATEWAY MENU}

Please choose one of the following options

P $>$ PacifiCat Library Catalog

I $>$ Information about the library

$\mathrm{R}>$ Reserves (Course Materials)

Research tools, including resources beyond campus collections

1. Expanded Academic \& Business Index ASAP (ARTICLES)

2. Periodical Indexes

3. Other Libraries

4. Gophers (Internet)

Q>QUIT

Figure 3. UOP 1996 Gateway Menu.

often not to use public terminals during the study period.

In 1996, we again monitored Innopac's transaction logs for 14 weeks from midFebruary to mid-May (see table 3). We assumed that the 1996 data would confirm our hypothesis with regards to menu search labels as well as permit us to take a more accurate look at staff, on-site patron and remote patron search patterns.

\section{Results}

\section{Patron Searches}

The results of the 1996 study were dramatically different than those of the pilot study (see table 4). Subject searches at public terminals increased $600 \%$ (from $3.7 \%$ to $23.7 \%$ ) while keyword searches dropped almost $12 \%$ and title searches dropped 10\%. Despite the decline, however, patrons still searched most often by keyword with title searches a close second. In both 1995 and 1996, UOP students used keyword more often than any other type of search. However, the dramatic rise in subject searching in 1996 appeared to confirm our hypothesis that the labeling of options on the search menu had an influence on the way users searched the catalog. The order in which the search options appeared on the screen (keyword before subject) was probably a contributing factor as well. Ballard (1994) found that keyword searching increased when it was listed as the first option on the search menu. If the subject option had come before the keyword option on the menu, perhaps keyword usage would have dropped even further.

Use of the online catalog's advanced features was quite low. Consistent with Ballard's findings, patrons were more likely than staff to rerun a failed title or subject search in keyword by pressing the " $w$ " key but they still used this feature less than $1 \%$ of the time (see table 4). More patrons at UOP utilized the limit feature (which narrows a search by material type, location, etc.) than did patrons at Adelphi, and remote users used it more often than onsite users.

Ballard $(1994,303)$ found that the biggest difference between staff and patron searches was that patrons were ten times more likely to get "unmanageably large" (over 500) search results. Patrons in our study retrieved record sets with 500 or more items $3.7 \%$ of the time, remote users retrieved large sets $4.7 \%$ of the time, and staff retrieved large sets $2.8 \%$ of the time (see table 5). However, while our analysis confirmed that public users are much more likely than staff to retrieve large sets, the actual numbers are small and did not seem to indicate a major problem. Public and staff alike retrieved zero hits about one third of the time $(34 \%$ and $35 \%$ respectively) with remote users faring slightly worse than onsite searchers (see table 6). UOP users were moderately more successful than Adelphi users, who 


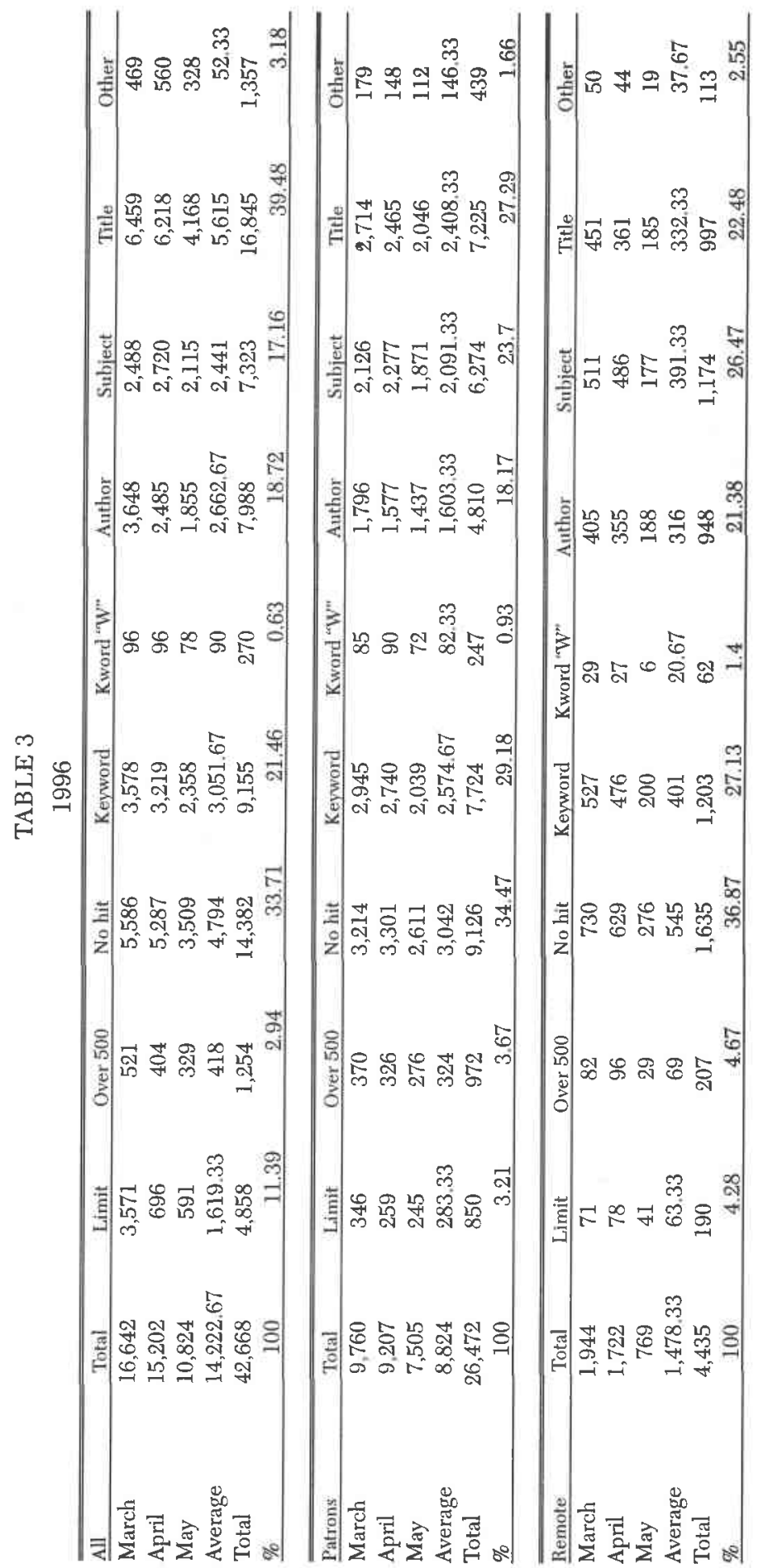




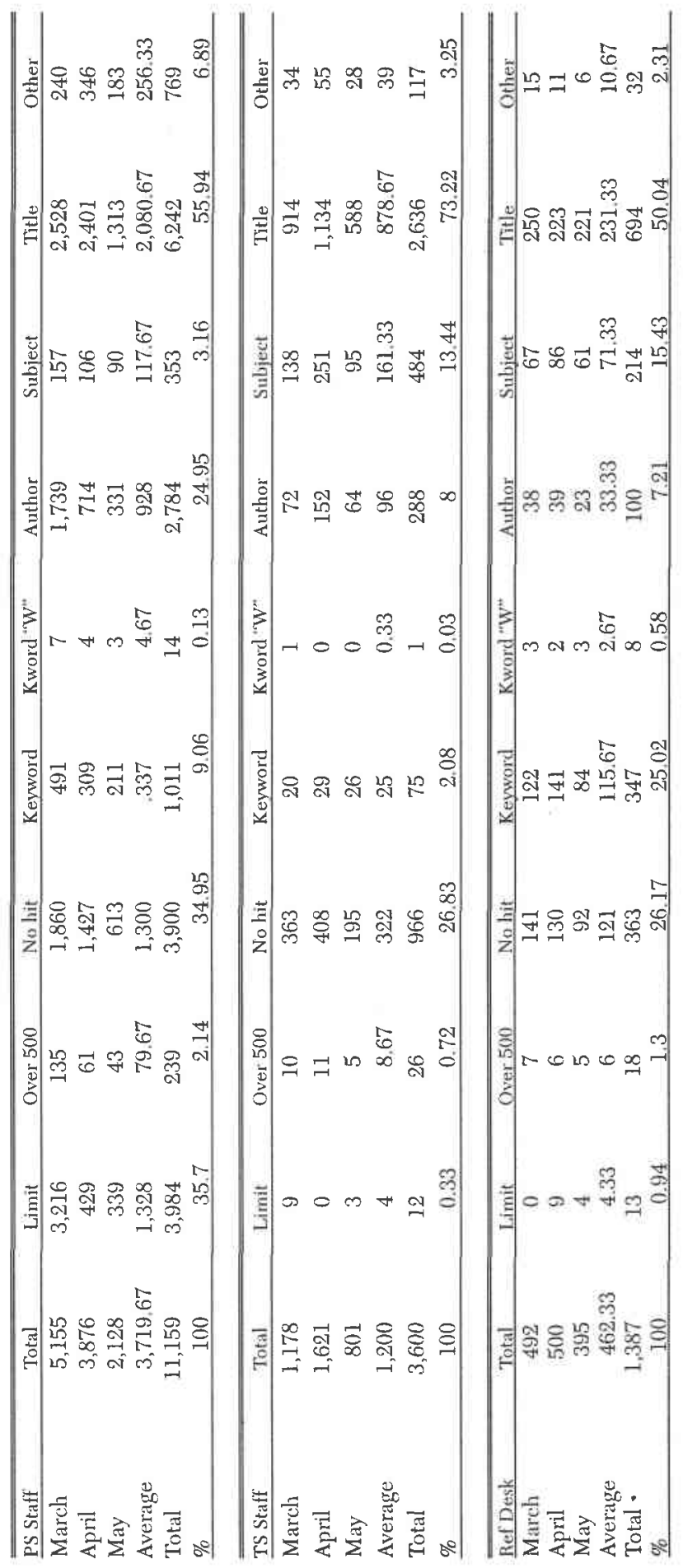


TABLE 4

Patron SEARCHES

\begin{tabular}{lrrrrrrrr}
\hline & \multicolumn{2}{c}{1995} & \multicolumn{2}{c}{ I996 } & \multicolumn{2}{c}{ Remote $^{1}$} & \multicolumn{2}{c}{ Adelphi } \\
& \multicolumn{1}{c}{$\%$} & \multicolumn{1}{c}{ Total } & \multicolumn{1}{c}{$\%$} & \multicolumn{1}{c}{ Total } & \multicolumn{1}{c}{$\%$} & \multicolumn{1}{c}{ Total } & \multicolumn{1}{c}{$\%$} & \multicolumn{1}{c}{ Total } \\
\hline Author & 15.8 & 10,135 & 18.2 & 4,810 & 21.4 & 948 & 21.0 & 18,600 \\
Title & 37.5 & 23,963 & 27.3 & 7,225 & 22.5 & 997 & 31.1 & 27,544 \\
Keyword & 41.0 & 26,233 & 29.2 & 7,724 & 27.1 & 1,203 & 8.3 & 7,354 \\
Subject & 3.7 & 2,374 & 23.7 & 6,274 & 26.5 & 1,174 & 35.5 & 31,512 \\
Other & 2.0 & 1,283 & 1.7 & 439 & 2.6 & 113 & 4.1 & 3,649 \\
Limit & 1.9 & 1,238 & 3.2 & 850 & 4.3 & 190 & 1.8 & 1,627 \\
Kword "w" & .6 & 350 & .9 & 247 & 1.4 & 62 & 1.8 & 1,581 \\
\hline
\end{tabular}

1 Subset of 1996 data

conducted zero hit searches $39 \%$ of the time. Librarians at the reference desk were the most successful, with a zero hit retrieval rate of $26 \%$.

Remote users performed $10 \%$ of the public searches in 1996. Because we had not gathered data separately for dial-up users in 1995, we could not analyze the impact of menu changes on this group's search strategies. Like onsite library users, remote users searched most often by keyword followed closely by subject (see table 4 ). They used Innopac's special features more often than on-site users, especially the limit feature. Not surprisingly, remote users relied on system help screens more often than other users (one-third of all help sessions were called up by remote users). Due to the fact that all remote users enter the system through one port, we were not able to determine whether the majority of our remote users were UOP students or unaffiliated users. We plan to look more closely at our remote users in a future transaction log study

\section{TABLE 5}

\begin{tabular}{lc}
\multicolumn{2}{c}{ OVER 500 RETRIEVED - 1996} \\
\hline Patrons & $3.7 \%$ \\
Remote & 4.7 \\
Tech, staff & .7 \\
Public staff & 2.1 \\
Reference Desk & 1.3 \\
\hline
\end{tabular}

\section{Reference Desk}

Data gathered from the reference desk terminals showed that $50.4 \%$ of the catalog searches conducted by reference librarians were title searches (see table 7). The preponderance of title searches is understandable given the number of inquiries received about library holdings. What was less clear was why librarians (15\%) searched by subject less often than patrons $(24 \%)$. When asked, several librarians said they preferred teaching students keyword searching because the Boolean logic capability was more important than the conceptually inclusive overview gained by browsing subject headings. They also felt that many students are confused by the list of subheadings retrieved with a subject search and found the keyword results more straightforward. Reference librarians were also less likely than patrons to use the limit and rerun-as-keyword features.

\section{TABLE 6}

ZERO HITS

\begin{tabular}{lccc}
\hline & $1995(\%)$ & $1996(\%)$ & Adelphi (\%) \\
\hline Patrons & 32 & 34 & 39 \\
Remote & n/a & 37 & n/a \\
Tech. staff & 36 & 27 & 23 \\
Public staff & 32 & 35 & 30 \\
Reference Desk & n/a & 26 & n/a \\
\hline
\end{tabular}


Staff Searching

While investigating the low use of other indexes by our technical services staff, we discovered that Innopac's transaction logs collected only catalog search data, not database search data. This was the biggest surprise (and disappointment) of our effort to replicate Ballard's study: Innopac's transaction logs do not capture staff searching as we normally think of it. Innopac transaction data, although extensive and detailed, are limited to catalog searches and do not include searches of the database, which typically constitute the bulk of staff searching activity at UOP.

The difference between the Innopac catalog and the Innopac database was not a distinction we were expecting to confront in our analysis. Innopac's bibliographic catalog, in addition to the public mode, can be searched in a staff mode that allows viewing of all fields in the MachineReadable Cataloging (MARC) format, as well as attached order records, item records, check-in records and so on, much of which understandably is hidden from public display. While searching the cata$\log$ is a quick and convenient way for library staff to retrieve certain records or information, it does not allow them to update any information or fields in retrieved records, and thus is seldom the preferred mode of searching by staff other than those doing reference or collection development work. Most staff searching, particularly in technical services, takes place within database update functionsin acquisitions, circulation, serials, and cataloging modules. These searches-to receive an ordered book, to check-in a periodical issue, to enter a new barcode and item status for a book returned from the bindery, to look for an existing record before creating an on-the-fly record within circulation-are ignored by Innopac's transactions logs. Yet these are the searches that would reveal the most about staff searching styles.

Ballard is vague on this distinction. $\mathrm{He}$ does not assert that his analysis included these types of staff searching, but neither does he explain how it is possible to analyze staff searching styles meaningfully
TABLE 7

REFERENCE DESK ${ }^{*}-1996$

\begin{tabular}{lc}
\hline Author & $7.2 \%$ \\
Title & 50.4 \\
Keyword & 25.0 \\
Subject & 15.4 \\
Other & 2.3 \\
Limit & .94 \\
Kword Aw@ & .58 \\
\hline
\end{tabular}

- 1995 not included due to skewed data

with logs that, in our view, exclude the bulk of searches that staff might perform on Innopac. Ballard includes a graph that illustrates technical services staff search percentages, and we can only surmise what would lead technical services or circulation staff to do so much title searching in the catalog and not in a database update mode. At UOP our technical services processes are much more tightly integrated than they were a few years ago. For instance, pre-order searching generally takes place seamlessly as part of the order entry transaction. Perhaps at Adelphi, pre-order searches are conducted as a separate process using the staff mode of the catalog. This type of difference in preorder processes would account for the substantial differences in technical services staff search patterns at the two libraries. It appears necessary to understand the organizational and procedural arrangements at libraries being compared before any meaningful conclusions about their staff searching patterns can be drawn.

Lacking database search data, an analysis of staff catalog searches is likely to be of limited value. However, a few observations are in order, if only to compare with Adelphi's findings. Our initial assumption that staff in public service areas (excluding the reference desk) searched primarily for specific items when searching the catalog proved correct (see table 8). Title and author searches accounted for $80.8 \%$ of their searches. Technical services staff also searched most often by title and author but performed four times as many subject 
TABLE 8

Public Services Staff Catalog Searches

\begin{tabular}{lrrrrrr}
\hline \hline & \multicolumn{2}{c}{1995} & \multicolumn{2}{c}{1996} & \multicolumn{2}{c}{ Adelphi } \\
& $\%$ & \multicolumn{1}{c}{ Total } & \multicolumn{1}{c}{$\%$} & \multicolumn{1}{c}{ Total } & \multicolumn{1}{c}{$\%$} & Total \\
\hline Author & 13.8 & 2,266 & 24.9 & 2,784 & 9.3 & 1,695 \\
Title & 63.1 & 10,365 & 55.9 & 6,242 & 48.8 & 8,859 \\
Keyword & 13.2 & 2,162 & 9.1 & 1,011 & 7.9 & 1,432 \\
Subject & 3.6 & 590 & 3.2 & 353 & 10.6 & 1,918 \\
Other & 6.3 & 1,032 & 6.9 & 769 & 23.5 & 4,261 \\
Limit & 4.0 & 656 & 35.7 & 3,984 & 4.8 & 876 \\
Kword “w” & .2 & 29 & .1 & 14 & .5 & 84 \\
\hline
\end{tabular}

searches as public staff (see table 9). Because librarians in technical services often use the catalog for collection development purposes, a higher incidence of subject searching was expected. Public services staff searched by keyword far less often than patrons. They also used the limit feature far more often than technical services staff. We speculate that this is attributable primarily to the staff in the Music/AV area who use the limit option to identify scores, videos, compact discs and other audio-visual materials.

A curious difference between staff searches at Adelphi and UOP was in the "Other" category. UOP public services staff seldom searched by call number, international standard number, bibliographic record number, or any other Innopac field. At Adelphi, these searches represented a sizable portion of public and technical services staff searches (approximately $31.9 \%$ ); at UOP these were a miniscule part (less than $5 \%$ ) of all staff search patterns. It is difficult for us to draw any conclusions about the discrepancy without more knowledge of the staffing arrangements and assignments at Adelphi. In the case of UOP, the low use of other indexes by public staff did not surprise us because the nature of their work-primarily circulation and reference activities-would not generally require them to employ these indexes.

\section{IMPACT OF ONLINE INDEXES}

A closer look at the $\mathbf{1 9 9 6}$ data revealed an unexpected result. In the process of comparing searches in the two years, we found that total searches had dropped nearly $50 \%$ : from 84,000 in 1995 to 42,700 in 1996 (see tables 1 and 3). Searches at public terminals had declined by almost $60 \%$ while staff searches fell $20 \%$. The number of searches by Technical Services staff remained nearly the same in 1996 but public services searching declined. However, because public service staff had been heavily involved in the 1995 collection development project, the subsequent decline in catalog searching made sense.

But it was unclear what could have accounted for the drastic decline in the number of patron searches. If the 1995 search total had been inflated by staff using public terminals for the collection development project, the 1996 total might have been expected to be down by a couple of thousand searches-but not 40,000. We rechecked our methodology, examined the transaction log setups, checked and double-checked the numbers, but found no detectable errors. There was no decrease in library users. In fact, the gate count and the reference question tallies indicated an increase in foot traffic during this time. Public terminals had been in constant use and we often observed students waiting to use a terminal.

The only change between the periods studied in 1995 and 1996 that could have had an impact on patron search preferences was the addition of the Information Access Company (IAC) full text Expanded Academic Index ASAP and Busi- 
TABLE 9

Technical Services Staff Catalog Searches

\begin{tabular}{lrrrrrr}
\hline & \multicolumn{2}{c}{1995} & \multicolumn{2}{c}{1996} & \multicolumn{2}{c}{ Adelphi } \\
& \multicolumn{1}{c}{$\%$} & Total & $\%$ & Total & \multicolumn{1}{c}{$\%$} & Total \\
\hline Author & 5.1 & 186 & 8.0 & 288 & 5.9 & 880 \\
Title & 72.0 & 2,628 & 73.2 & 2,636 & 34.1 & 5,091 \\
Keyword & 3.3 & 121 & 2.1 & 75 & 1.4 & 211 \\
Subject & 15.5 & 564 & 13.4 & 484 & 3.7 & 550 \\
Other & 4.1 & 149 & 3.3 & 117 & 54.8 & 8,176 \\
Limit & .2 & 8 & .3 & 12 & .4 & 61 \\
Kword "w" & .1 & 2 & .1 & 1 & .1 & 13 \\
\hline
\end{tabular}

ness Index ASAP to our library's catalog gateway in December I995. The IAC indexes were first made available through the online catalog in December 1994, but student use was minimal. Student awareness and enthusiasm increased considerably when the full text version with the article print station became available in late 1995. We knew from observation and public feedback that the online indexes had become tremendously popular with our students. We examined the IAC connect logs and the Innopac gateway logs to see whether they confirmed our suspicion that the indexes were the cause of such a drastic decline in library catalog searching. Unfortunately, the number of connections made to outside databases had not been tracked until 1996, and even this data was inconclusive. Both IAC and Innopac $\log$ the number of connections made to IAC databases from Innopac. However, the number of connections does not accurately reflect the number of students using the database during one session. Students often walk up to a terminal already connected to IAC. The number of searches performed on the databases are not tracked, only the initial connection and the number of minutes the connection is maintained. There was no objective way to determine whether students had performed 40,000 searches in the IAC indexes rather than in the library's catalog during the three month study. However, we had observed students who formerly had to be led to peri- odical indexes now beginning their research with the IAC indexes. We could only deduce that students were searching the online databases at least as often as they searched Innopac.

Growing student use of the Expanded Academic Index and Business Index might have also contributed to the subsequent increase in subject searching on Innopac. Because the default search for both indexes is a subject search, students were becoming familiar with $L C S H$, which is the thesaurus of both indexes. Students in library instruction classes were increasingly taught how to understand and use LCSH headings and subdivisions in order to use the IAC databases. There are no hard data to support the idea that our students' increasing familiarity with the subject searching of online indexes increased their subject searching of the catalog but there is anecdotal evidence.

\section{Replication Difficulties}

In our two-year endeavor to provide comparative data on the search styles of patrons and staff, we discovered that replicating a study is not nearly as straightforward as we had initially thought. Despite the similarities in size of the institution, library holdings, systems, and research methodologies, it was unexpectedly difficult to compare data from the two libraries with a high degree of confidence. This was due to a variety of 
factors. Differences in menu design and labels, for example, appear to have an impact on patron search patterns. We were not aware of nor did we think to consider that the differences in the search screens of the two institutions might affect the results so dramatically. Another factor was bibliographic instruction. At UOP, library instruction appeared to have some influence on student search strategies, yet we knew nothing of Adelphi's instructional programs. Most of our students participated in hands-on instruction sessions where librarians taught both subject and keyword search strategies. Even the way we staffed the reference desk (one librarian per shift; no staff or paraprofessionals) may have had an impact on the search strategies of our users.

Comparing data from studies of two libraries is understandably problematic. But we also found it surprisingly difficult to compare year to year data at the same institution. This was primarily due to a continually changing technological environment. At UOP, the number of terminals and PCs available for student and staff searching have changed constantly. For example, in 1996 we added four networked PCs for public access to Innopac (three after the period of the study) and removed a dumb catalog terminal. In the coming year, three networked workstations will feature Innopac's new graphical interface. This will make the task of tracking and interpreting patron search patterns even more challenging.

We also found that it was not easy to isolate the terminal groups or gather valid data or ensure staff compliance with our instructions. And while it might appear straightforward and gratifyingly scientific to analyze reams of computer-generated data, there are multiple variables that have an influence on the numbers collected by the system. These variables must be controlled to ensure accurate results. If librarians were scientists working in laboratories, we could closely control or isolate the variables and regulate our environments. But we work in living laboratories, vibrant and dynamic and elastic. As such, replications of transaction log studies will never be as scientifically rigorous as we might wish.

Despite the problems, a transaction log analysis remains one of the best and most accurate ways to examine basic user search patterns. While the number of variables that might affect results cannot all be controlled, the results are still valuable and illuminating. As we discovered in 1995, a pilot study will help expose the most serious problems. The replication of previous TLA studies is important, not only to build up a body of reliable research but also to test the validity of the original research. Through our study, new information about the Innopac's inability to collect full staff searching statistics came to light, which is important for future studies.

By replicating Ballard's study of Adelphi users we uncovered a wealth of information about our own library users, how they search our system, and how their strategies are affected by a variety of elements. We learned how their search patterns compared with those of users at a similar institution and sought explanations for similarities as well as differences. By comparing our data with that of another library, we were able to question our results more rigorously and use our knowledge more effectively.

\section{Conclusions}

The most unexpected and intriguing aspect of our study was the discovery of the rise in student use of online periodical databases and the subsequent impact on catalog searches. We were surprised by the dramatic increase and had we had any hint of the apparent impact of the online indexes on student search preferences, we would have closely tracked the number and length of connections made to the indexes from the beginning of the study. Admittedly, the number of connections made to the index database is not comparable to the number of Innopac searches. However, it would have provided a baseline from which to measure subsequent use. A substantial increase in the number of connections made in 1996 compared to the number made in 1995 might have supported our supposition that the online 
indexes were the primary cause of the decrease in total searches in our catalog.

Our data also suggest that the shift from a traditional online catalog menu to a gateway menu might have been a contributing factor in the increased use of online indexes. On the previous menu, the option to connect to online databases was buried deep in a long list of search options and did not specify periodical indexes (see figure 1). On the new gateway menu, the IAC indexes were given high visibility and a more precise label (see figure 3 ). As stated previously, Ballard noted an increase in keyword searching after it was placed first on the list of search options. In addition, we found that the labeling of individual search options had an impact on search styles. Subject searching rose dramatically when the search option was changed from its more precise and descriptive label, "Library of Congress Subject Heading," to the less precise but more comprehensible "Subject" label. While the former label was more accurate, it obscured the meaning for the typical user.

As with most research projects, our study prompted more questions than answers. We discovered how little we knew about our remote users, how impossible it was to study staff search patterns with incomplete transactions logs, how technology had unintended impacts on systems and the users of those systems. Despite the obstacles and setbacks, our attempt to replicate a transaction log study was of great benefit to our library, and we encourage other libraries to improve on our effort.

\section{Works Cited}

Ballard, Terry. 1994. Comparative searching styles of patrons and staff. Library resources \& technical services 38: 293-305.

Cherry, Joan M. 1992. Improving subject access in OPACs: An exploratory study of conversion of users' queries. The journal of academic librarianship 18: 95-99.

Connaway, Lynn Silipigni, John M. Budd, and Thomas R. Kochtanek. 1995. An investigation of the use of an online catalog: User characteristics and transaction log analy- sis. Library resources \& technical services 39: 142-52.

Hunter, Rhonda N. 1991. Successes and failures of patrons searching the online cata$\log$ at a large academic library: A transaction $\log$ analysis. $R Q$ 31: 395-402.

Larson, Ray R. 1991a. Between Scylla and Charybdis: Subject searching in the online catalog. Advances in librarianship 15: 175-236.

-. 1991b. The decline of subject searching: Long term trends and patterns of index use in an online catalog. Journal of the American Society for Information Science 42: 197-215.

Markey, Karen. 1984. Subject searching in library catalogs: Before and after the introduction of online catalogs. Dublin, Ohio: OCLC Online Computer Library Center.

Martin, Thomas H., John C. Wyman, and Kumud Madhok. 1983. Feedback and exploratory mechanisms for assisting library staff improve on line catalog searching. Syracuse: Syracuse University, ED 258577

Peters, Thomas A. 1989, When smart people fail: An analysis of the transaction log of an online public access catalog. The journal of academic librarianship 1.5: 267-73.

Peters, Thomas A. 1993. The history and development of transaction log analysis. $\mathrm{Li}$ brary hi tech 11: 41-66.

Simpson, Charles W. 1989. OPAC Transaction Log Analysis: The First Decade. In Advances in Library Automation and Networking 3: 35-67. Greenwich, CT: JAI Press.

Tillotson, Joy. 1995. Is keyword searching the answer? College \& research libraries 56: 199-206

Tolle, John E. 1983. Understanding patrons' use of online catalogs: Transaction log analysis of the search method. In Productivity in the information age: Proceedings of the 46th ASIS annual meeting, Washington, D.C., October 2-6, 1983: 167-71. White Plains, N.Y.: Knowledge Industry Publications.

Wallace, Patricia M. 1993. How do patrons search the online catalog when no one's looking? Transaction $\log$ analysis and implications for bibliographic instruction and system design. $R Q$ 33: 239-52.

Zink, Steven D. 1991. Monitoring user search success through transaction $\log$ analysis: The WolfPAC example. Reference services review 19: 49-56. 